\title{
Controlling of UPFC parameters using fuzzy logic based supplementary damping controller
}

\author{
Bairu Vijaykumar, Nandiraju Venkata Srikanth \\ Electrical Engineering Department, National Institute of Technology, Warangal, A.P, India-506004
}

Email address:

bairuvijaykumar@gmail.com(B. Vijaykumar)

\section{To cite this article:}

Bairu Vijaykumar, Nandiraju Venkata Srikanth. Controlling of UPFC Parameters Using Fuzzy Logic Based Supplementary Damping Controller. International Journal of Energy and Power Engineering. Vol. 2, No. 4, 2013, pp. 147-153. doi: 10.11648/j.ijepe.20130204.12

\begin{abstract}
In this paper, use of the additional supplementary damping controller for unified power flow controller (UPFC) to damp out low frequency oscillations in a heavily loaded power system is investigated. Normal damping controllers are inferior when the power system is subjected to large and fast changing loads. In order to handle the situation, an additional supplementary damping controller for UPFC is designed using Fuzzy logic technique. The effectiveness of the proposed controller on damping low frequency oscillations is tested and demonstrated through simulation studies for single machine connected to infinite bus power system (SMIB). In addition power system response with UPFC damping controller \& Fuzzy logic based supplementary damping controller (FLSDC) are compared at various loading conditions. It can be concluded that Fuzzy logic based supplementary damping controller improves greatly the system stability under heavily loaded conditions.
\end{abstract}

Keywords: UPFC, SMIB, FLSDC

\section{Introduction}

The stability of a system can be defined as the ability of a system to regain equilibrium condition when subjected to a disturbance. Power is generated by synchronous generators that operate in synchronism with the rest of the system. A generator is synchronized with a bus when both of them have same voltage, frequency and phase sequence. Thus the power system stability can be defined as the ability of the power system to return to steady state without losing synchronism. Usually power system stability is categorized into steady state, transient and dynamic stability [1], [2].

The dynamic stability (also known as small-signal stability) is the ability of a power system to maintain equilibrium state when subjected to continuous small disturbances. These small disturbances occur due to random fluctuations in loads and generation levels. In an interconnected power system, these random variations can lead catastrophic failures. The disturbances are considered sufficiently small for linearization of system equations to be permissible. The instability of power system may lead to the steady increment in rotor angle due to lack of sufficient synchronizing torque and increasing amplitude of rotor oscillations due to lack of sufficient damping torque.
The nature of system response to small disturbances depends on a number of factors such as, the type of generator excitation controls used, initial operating conditions of the system and transmission system used. In today's practical power system, dynamic stability is largely a problem of insufficient damping of oscillations.

Modern Power Systems are equipped with fast acting static excitation systems, as these units become a major part of the generating capacity; they have a great impact upon the dynamic stability of power systems. They introduce negative damping at the electro- mechanical oscillation frequencies of the machines in the range of $0.1 \mathrm{~Hz}$ to $2.5 \mathrm{~Hz}$. They make the system unstable under local and inter-area modes of oscillations. Particularly when the system is weak and has weak tie lines, even a small disturbance will create instability in the system. The purpose of dynamic stability is to analyze the dynamic performance of a synchronous machine under small perturbations. Since the machine must remain in synchronism under small perturbations, it is essential to have positive damping for the machine. The damping torque of the synchronous machine is affected by a number of factors viz. excitation controls, machine loading, Power System Stabilizer parameters and nature of loads etc. Hence, a detail-linearized model is required to 
analyze the dynamic stability. Power System Stabilizers were developed to dampening off these oscillations by modulating generator excitation and introducing positive damping to the system.

Many efforts are made to replace the conventional power system stabilizers with Fuzzy Logic Based, Flexible AC Transmission Systems (FACTS) based and Artificial Neural Network based stabilizers. This is because of the fact that the above new approaches are superior to algorithmic methods and are adaptive in nature. They also have fast response with reduced transients and can also adapt themselves to the non-linearity in the system. The drawback of the fuzzy based and adaptive fuzzy based stabilizers is in the formation of rule base. This rule base may vary from system to system. The limitations of ANN based stabilizers are in its learning ability and suitable learning algorithms are required and this may even system dependent. Many simulated studies are made in this direction and good results are obtained [3] to [11].

Flexible AC Transmission Systems (FACTS) are new devices emanating from recent advanced technologies that are capable of altering voltage magnitude, phase angle and/or impedance at particular points in power systems. Their fast response offers a high potential for power system stability enhancement apart from steady-state flow control. The simulated studies of FACTS devices reveal the fact that they improve the dynamic stability of power system if applied properly.

UPFC (Unified power flow control) is a combined series shunt controller. It is the most powerful FACTS device. Gyugyi proposed the Unified Power Flow Controller which is the new type generation of FACTS devices in the year 1991. UPFC being emerged as one of the effective controllers for controlling and optimization of the power flow in the electrical power transmission systems, here line impedance, terminal voltages, and voltage angle can be controlled by UPFC. It is a multiple-functional FACTS controller with primary duty to be power flow control. The secondary functions of the UPFC can be voltage control, transient stability improvement, oscillation damping etc. Recently, there has been a growing interest in studying the UPFC, its modeling its basic function to control the power flow and its capability to increase system transient stability [12].

\section{The Unified Philips-Heffron Model of the Power System Installed with UPFC}

UPFC consists of a combination of a shunt and series branches connected through the dc capacitor The series connected inverter injects a voltage with controllable magnitude and phase angle in series with the transmission line, therefore providing real and reactive power to the transmission line. The shunt-connected inverter provides the real power drawn by the series branch and the losses and can independently provide reactive compensation to the system.

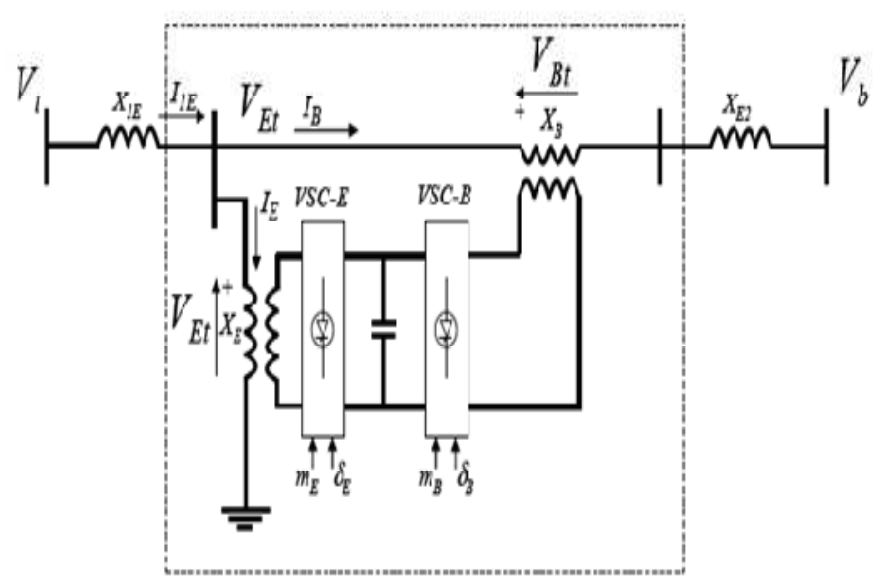

Fig. 1. UPFC installed in Single-machine Infinite bus system

The UPFC model is a combination of the synchronous static compensator (STATCOM) and static series synchronous compensator (SSSC). These two are coupled via a common de link to allow bi-directional flow of power between series output terminals of SSSC and the shunt output terminals of STATCOM. These are controlled to provide concurrent real and reactive power compensation without any external electric source [11]. The UPFC by means of angularly unconstrained series voltage injection is able to control, concurrently or selectively the transmission line voltage, impedance and angle or alternatively, real and reactive power flow in transmission line. The UPFC may also provide independently controllable shunt reactive compensation. By controlling the voltage at the bus where UPFC installed is controlled through reactive power compensation. Figure 1 shows Single-machine connected to Infinite bus power system installed with UPFC [7]. Where $\mathrm{m}_{\mathrm{B}}, \mathrm{m}_{\mathrm{E}}, \delta_{\mathrm{B}}$ and $\delta_{\mathrm{E}}$ are amplitude modulation ratio and phase angle of the control signal of series converter and shunt converter respectively. These four are input control signals of the UPFC.

\subsection{Mathematical Modelling of SMIB Installed with UPFC}

The non linear differential equations from which phillips-heffron linear model of a Single-machine Infinite bus power system is derived are as follows.

$$
\begin{gathered}
\dot{\delta}=\omega_{\circ} \Delta \omega \\
\dot{\omega}=\left(P_{m}-P_{e}-D \omega\right) / 2 H \\
\dot{E}_{q}^{\prime}=\left(-E_{q}+E_{f d}\right) / 2 T_{d o}^{\prime} \\
\dot{E}_{f d}=-\frac{1}{T_{A}} \Delta E_{f d}-\frac{K_{A}}{T_{A}}\left(v_{t o}-v_{t}\right)
\end{gathered}
$$


By linearising above equations we can obtain

$$
\begin{aligned}
& \Delta \dot{\delta}=\omega_{\circ} \Delta \omega \\
& \begin{array}{l}
\Delta \dot{\omega}=\left(P_{m}-P_{e}-D \Delta \omega\right) / 2 H \\
\Delta \dot{E}_{q}^{\prime}=\left(-\Delta E_{q}+\Delta E_{f d}\right) / T_{d o}^{\prime}
\end{array} \\
& \begin{array}{l}
\Delta \dot{\omega}=\left(P_{m}-P_{e}-D \Delta \omega\right) / 2 H \\
\Delta \dot{E}_{q}^{\prime}=\left(-\Delta E_{q}+\Delta E_{f d}\right) / T_{d o}^{\prime}
\end{array} \\
& \Delta P_{e}=K_{1}^{\Delta \delta+} K_{2} \Delta E_{q}^{\prime}+K_{p d} \Delta v_{d c}{ }^{+} K_{p e} \Delta m_{E}+K_{p \delta e} \Delta \delta_{e}+K_{p b} \Delta m_{B}+K_{p \delta b} \Delta \delta_{B} \\
& \Delta E_{q}^{\prime}=K_{4} \Delta \delta+K_{3} \Delta E_{q}^{\prime}+K_{q d} \Delta v_{d c}+K_{q e} \Delta m_{E}+K_{q \dot{\varepsilon}} \Delta \delta_{E}+K_{q b} \Delta m_{B}+K_{q \delta} \Delta \delta_{B} \\
& \Delta V_{t}=K_{5} \Delta \delta+K_{6} \Delta E_{q}^{\prime}+K_{v d} \Delta v_{d c}+K_{v e} \Delta m_{E}+K_{v \delta e} \Delta \delta_{e}+K_{v b} \Delta m_{B}+K_{v a b} \Delta \delta_{B} \\
& \Delta \dot{\boldsymbol{v}}_{d c}=K_{7} \Delta \delta+K_{8} \Delta E_{q}^{\prime}-K_{9} \Delta v_{d c}+K_{c e} \Delta m_{E}+K_{c \dot{ }} \Delta \delta_{E}+K_{c b} \Delta m_{B}+K_{c \varnothing} \Delta \delta_{B}
\end{aligned}
$$

Substituting eqn. 3 in into eqn. 2 we can obtain the state variable equations of power system installed with UPFC. Where $\Delta \mathrm{m}_{\mathrm{E}}, \Delta \mathrm{m}_{\mathrm{B}}, \Delta \delta_{\mathrm{E}}$ and $\Delta \delta_{\mathrm{B}}$ are linearization of input control signals of the UPFC. From the above equations linearized model of the power system can be obtained and it is used in power system stability studies.

$$
\begin{aligned}
& {\left[\begin{array}{c}
\Delta \dot{\delta} \\
\Delta \dot{\omega} \\
\Delta \dot{E}_{q} \\
\Delta \dot{E}_{f d} \\
\Delta \dot{v}_{d c}
\end{array}\right]=\left[\begin{array}{ccccc}
0 & \omega_{0} & 0 & 0 & 0 \\
-\frac{K_{1}}{M} & -\frac{D}{M} & -\frac{K_{2}}{M} & 0 & -\frac{K_{p d}}{M} \\
-\frac{K_{4}}{T_{d o}^{\prime}} & 0 & -\frac{K_{3}}{T_{d 0}^{\prime}} & \frac{1}{T_{d o}^{\prime}} & -\frac{K_{q d}}{T_{d o}^{\prime}} \\
-\frac{K_{A} K_{5}}{T_{A}} & 0 & -\frac{K_{A} K_{6}}{T_{A}} & -\frac{1}{T_{A}} & -\frac{K_{A} K_{v d}}{T_{A}} \\
K_{7} & 0 & K_{8} & 0 & -K_{9}
\end{array}\right] \times\left[\begin{array}{c}
\Delta \delta \\
\Delta \omega \\
\Delta E_{q}^{\prime} \\
\Delta E_{f d} \\
\Delta v_{d c}
\end{array}\right]} \\
& +\left[\begin{array}{cccc}
0 & 0 & 0 & 0 \\
-\frac{K_{p e}}{M} & -\frac{K_{p \delta e}}{M} & -\frac{K_{p b}}{M} & -\frac{K_{p \delta b}}{M} \\
-\frac{K_{q e}}{T_{d o}^{\prime}} & -\frac{K_{q \delta e}}{T_{d 0}^{\prime}} & -\frac{K_{q b}}{T_{d o}^{\prime}} & -\frac{K_{q \delta b}}{T_{d 0}^{\prime}} \\
-\frac{K_{A} K_{v c}}{T_{A}} & -\frac{K_{A} K_{v \delta c}}{T_{A}} & -\frac{K_{A} K_{v b}}{T_{A}} & -\frac{K_{A} K_{v \delta b}}{T_{A}} \\
K_{c e} & K_{c \delta e} & K_{c b} & K_{c \delta b}
\end{array}\right]\left[\begin{array}{l}
\Delta m_{E} \\
\Delta \delta_{E} \\
\Delta m_{B} \\
\Delta \delta_{B}
\end{array}\right]
\end{aligned}
$$

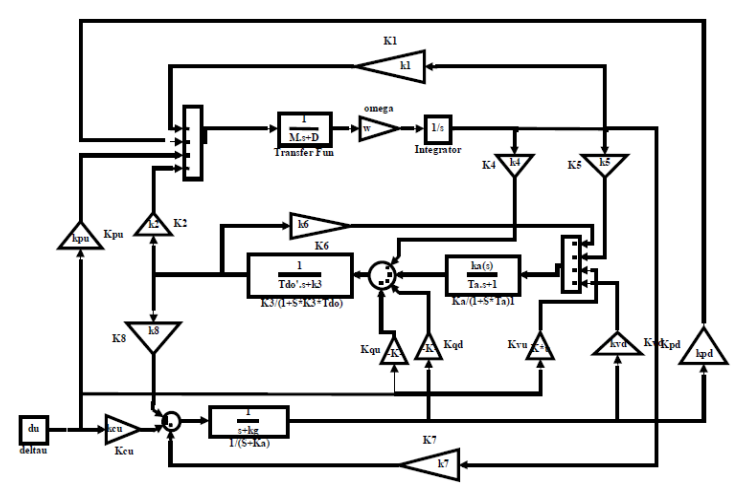

Fig.2. Phillips-Heffron model of power system installed with UPFC

\section{UPFC with Fuzzy Logic Based Supplementary Damping Controller}

\subsection{Design of Damping Controllers}

The damping controllers are designed to produce an electrical torque in phase with the speed deviation. The four control parameters of the UPFC $\left(\mathrm{m}_{\mathrm{B}}, \mathrm{m}_{\mathrm{E}}, \delta_{\mathrm{B}}\right.$ and $\left.\delta_{\mathrm{E}}\right)$ can be modulated in order to produce the damping torque. The speed deviation $\Delta \omega$ is considered as the input to the damping controllers. The four alternative UPFC based damping controllers are examined in this research.

The structure of UPFC based damping controller is shown in Fig3. It consists of gain, signal washout and phase compensator blocks. The signal washout is the high pass filter that prevents steady changes in the speed from modifying the UPFC input parameter. The value of the washout time constant $T_{w}$ should be high enough to allow signals associated with oscillations in rotor speed to pass unchanged. From the viewpoint of the washout function, the value of $\mathrm{T}_{\mathrm{w}}$ is not critical and may be in the range of 1$20 \mathrm{sec} . \mathrm{T}_{\mathrm{w}}$ is equal to $10 \mathrm{sec}$ is chosen in the present research [13].

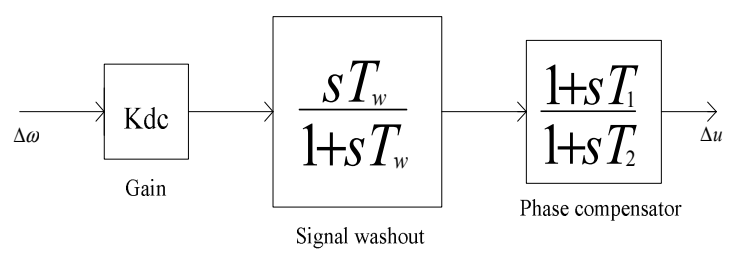

Fig.3. Structure of UPFC based damping controller 


\subsection{Fuzzy logic Controller}

In the conventional control, the amount of control is determined in relation to a number of data inputs using a set of equations to express the entire control process. Expressing human experience in the form of a mathematical formula is a very difficult task if not an impossible one.

Fuzzy logic provides a simple tool to interpret this experience into reality. Fuzzy Logic Controllers (FLC) are rule-based controllers. The structure of the FLC resembles that of a knowledge based controller except that the FLC utilizes the principles of the fuzzy set theory in its data representation and its logic. The basic configuration of the FLC can be simply represented in four parts as shown in Fig.4 [14].

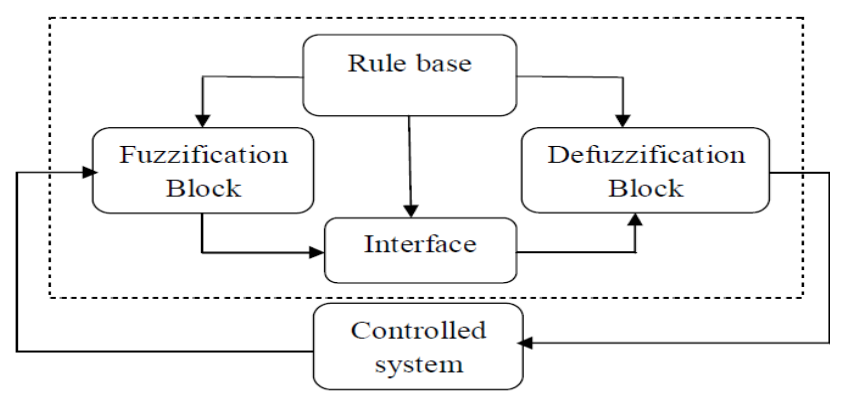

Fig.4. FLC building blocks

Fuzzification block: The functions of this block are first to read, measure and scale the control variable (speed, acceleration) and second to convert the measured numerical values to the corresponding linguistic variables.

Rule base: This consists of the definitions of the fuzzy membership functions defined for each control variables and the necessary rules that specify the control goals using linguistic variables.

Inference mechanism: It should be capable of simulating human decision making and influencing the control actions based on fuzzy logic. In the inference mechanism, rules are defined by the user. On the bases of these rules, output of fuzzy controller is controlled.

Defuzzification block: This block converts the inferred decision from the linguistic variables back the numerical values. There are so many methods to execute the Defuzzification, viz., centre of gravity method, centre of singleton method, maximum methods, the marginal properties of the centroid methods \& so on.

\subsection{Fuzzy Logic Design}

Fuzzy logic controller based on mamdani type fuzzy logic controller is used in this research work to damp power system oscillations in the study system. Fig.5 shows structure of fuzzy logic controller. It uses angular speed and rate change of angular speed as its signals. Each input variables are assigned to seven linguistics variables, therefore 49 rules are formulated. These rules are formulated with a simple IF-THEN structure. They map the inputs states into 49 output conditions. Table-I shows membership function rules of the Fuzzy logic controller. The rules of this table can be formed based on experience and simulation results obtained from the system. Fig.6 shows Simulink diagram of SMIB with Fuzzy Logic based Supplementary damping controller.

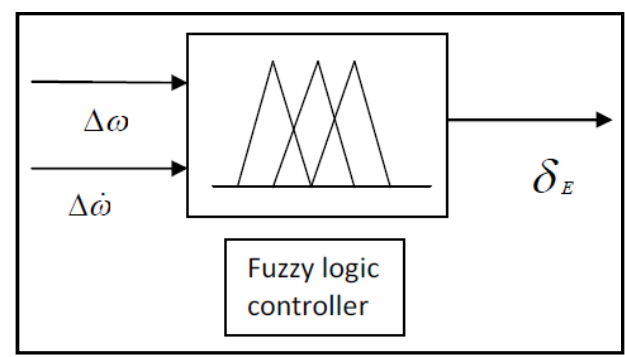

Fig.5. Fuzzy logic based supplementary damping controller

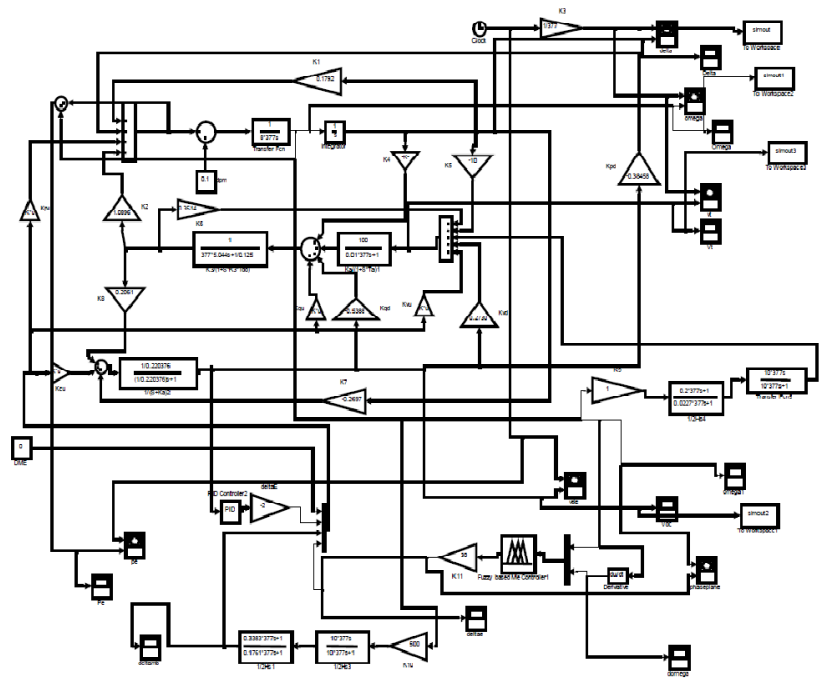

Fig.6. SIMULINK diagram of SMIB with FLSDC

Table-I. Membership function rules

\begin{tabular}{cccccccc}
\hline$\Delta \omega$ & NB & NM & NS & ZE & PS & PM & PB \\
\hline NB & PM & NB & NB & ZE & ZE & PS & NS \\
NM & NS & NB & NS & NS & PS & NS & ZE \\
NS & NB & NS & PS & PS & PS & NB & ZE \\
ZE & NB & NB & NB & ZE & NS & NB & PS \\
PS & NM & NB & NM & NM & NM & PB & PB \\
PM & NM & NS & NB & NS & PM & PB & PB \\
PB & ZE & PB & NB & PS & PM & PB & PB \\
\hline
\end{tabular}

\section{Results \& Analysis}

The Heffron-Philips model of a SMIB installed with UPFC has been simulated using Matlab-Simulink software with estimated $\mathrm{K}$ constant values. Fuzzy logic based supplementary damping controller is introduced to improve the Performance of the system. Response of the SMIB system with and without FLSDC is analyzed for various test conditions .i.e. large loading and very large loading 


\subsection{For no Damping Controller Condition}

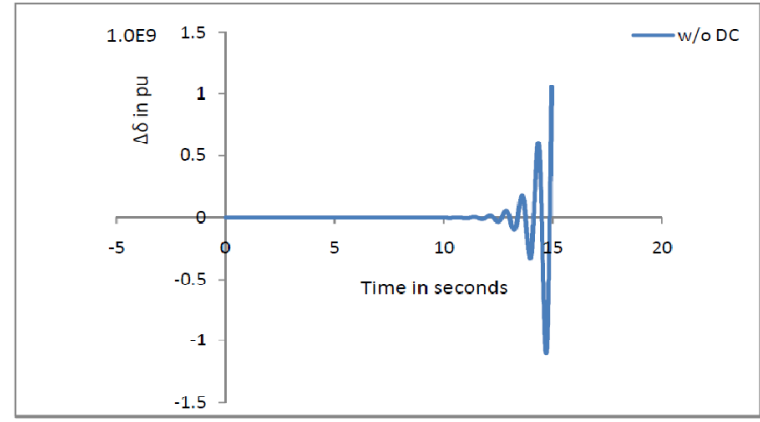

Fig. 7. Variation of Rotor angle

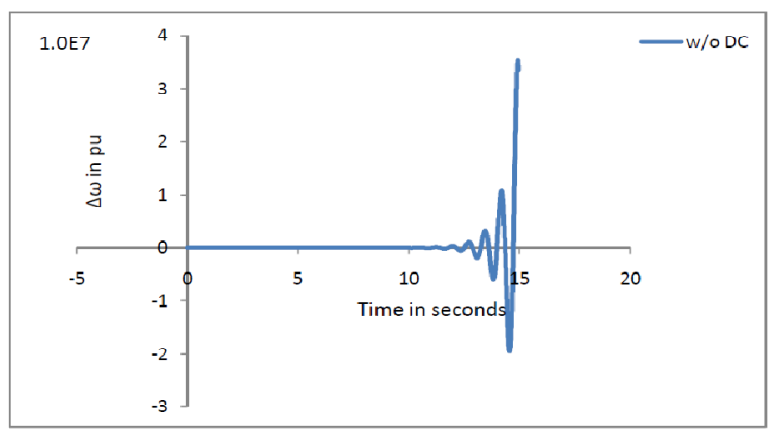

Fig.8. Variation of Angular velocity

From figure $7 \& 8$ it can be observed without damping controller $\Delta \delta$ and $\Delta \omega$ are increasing hence the system is unstable.

\subsection{For large Loading Condition}

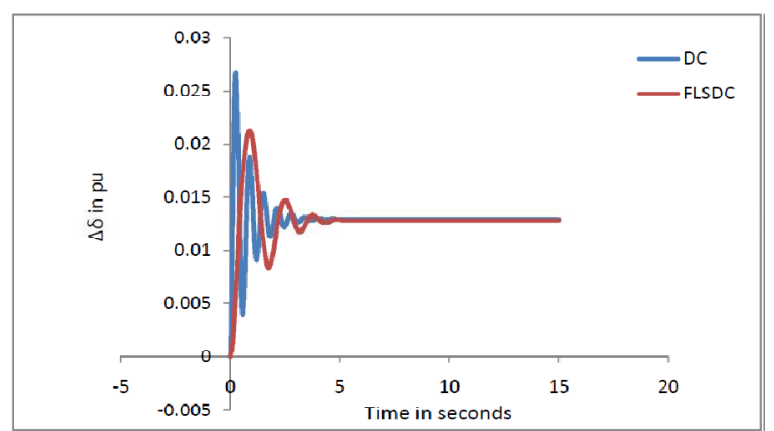

Fig.9. Variation of Rotor angle

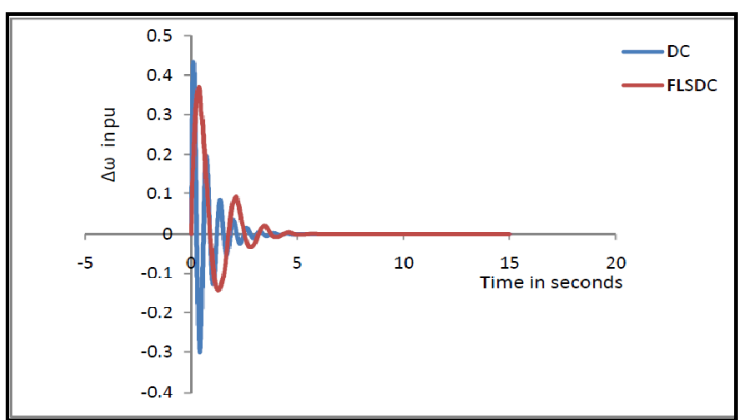

Fig.10. Variation of Angular velocity

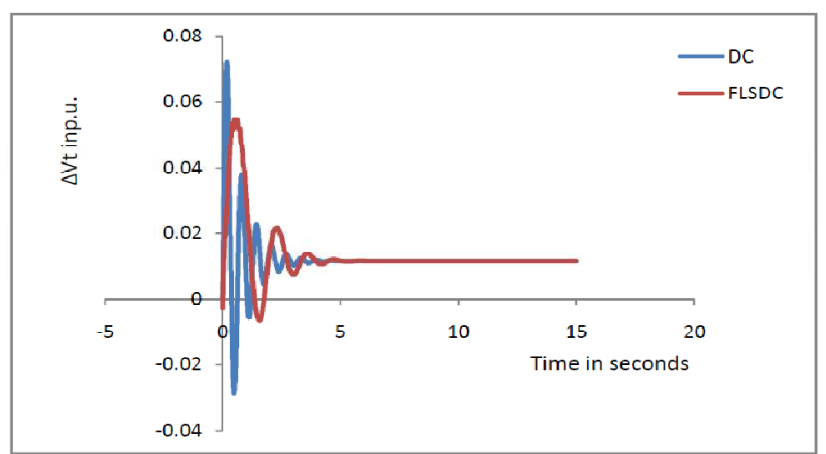

Fig.11. Variation of Terminal voltage

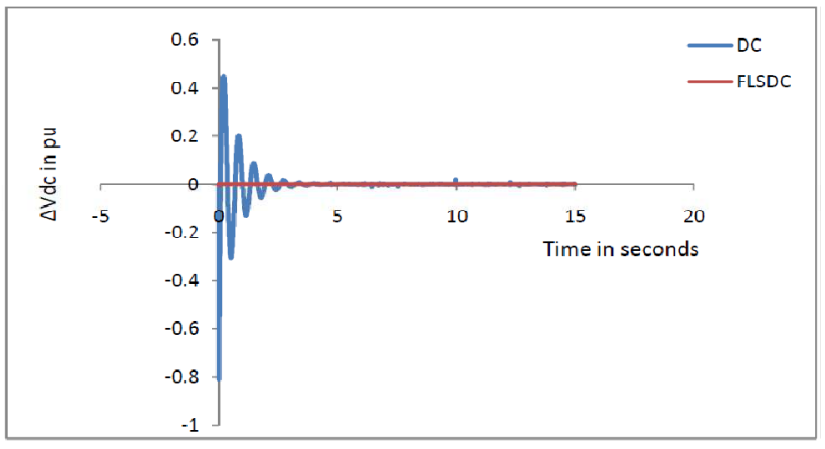

Fig.12. Variation of DC voltage

From figure 9, 10, $11 \& 12$ it can be observed both Damping controller and Fuzzy logic based supplementary damping controller are able to stabilize the system. But the overshoot in the system response is reduced with FSLDC.

\subsection{For Very large Loading Condition}

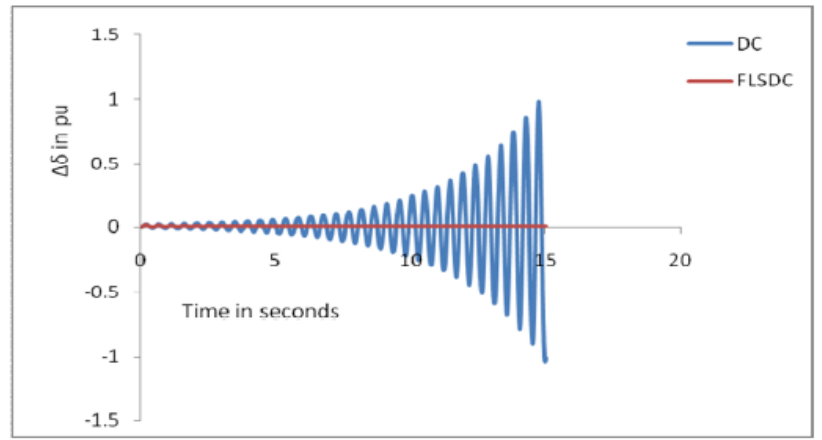

Fig.13. Variation of Rotor angle

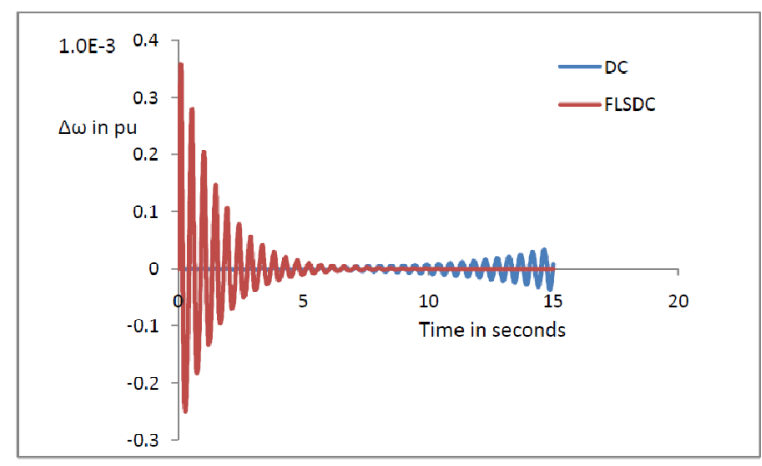

Fig.14. Variation of Angular velocity 


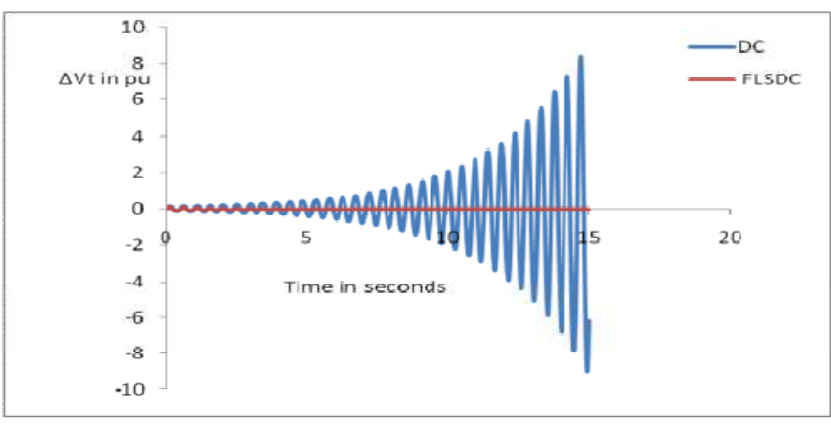

Fig.15. Variation of Terminal voltage

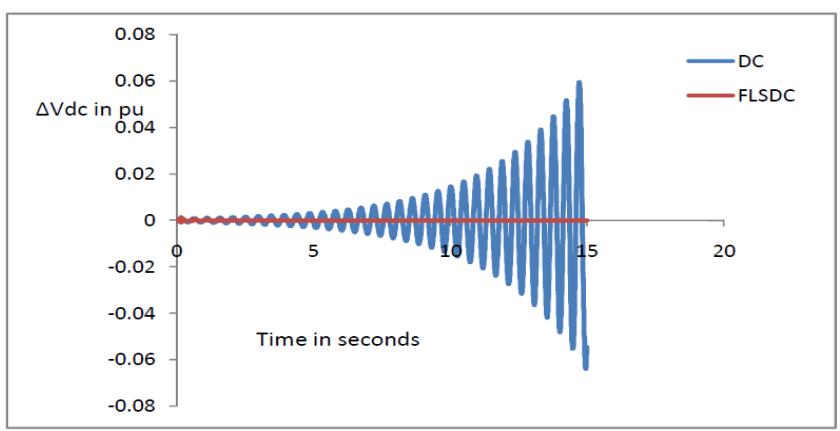

Fig.16. Variation of DC voltage

From figure $13,14,15 \& 16$ it can be observed Damping controller is unable to stabilize the system under very large loading conditions where as Fuzzy logic based supplementary damping controller is able to stabilize the system.

\section{Conclusion}

DC voltage regulator of UPFC negatively interacts with the power system stabilizers and hence, affects the stability of power system. Therefore a damping controller is designed for UPFC in order to improve the dynamic stability of power system, but this damping controller may not be effective for very large loading conditions. Hence, Fuzzy logic based supplementary damping controller (FLSDC) is designed in order to stabilize the low frequency oscillations of power system for large loading conditions very effectively.

\section{Nomenclature}

$\mathrm{m}_{\mathrm{B}}$ : Modulation index of series converter

$\mathrm{m}_{\mathrm{E}}$ : $\quad$ Modulation index of shunt converter

$\delta_{\mathrm{B}}$ : $\quad$ Phase angle of series converter voltage

$\delta_{\mathrm{E}}$ : $\quad$ Phase angle of shunt converter voltage

D: Damping constant

M: Inertia constant $(\mathrm{M}=2 \mathrm{H})$

$\mathrm{V}_{\mathrm{dc}}: \quad$ Voltage at dc link

$\mathrm{V}_{\mathrm{t}}$ : Terminal voltage of generator

W/o DC: Without Damping controller

DC: $\quad$ With Damping controller

FLSDC: Fuzzy logic based supplementary Damping controller

\section{Appendix}

The nominal parameters and the operating conditions of the system are given here.

$\begin{array}{lll}\text { Generator } & \mathrm{M}=2 \mathrm{H}=8 \mathrm{MJ} / \mathrm{MVA} & \\ & \mathrm{D}=0 & \mathrm{~T}_{\mathrm{do}}^{\prime}=5.044 \mathrm{~s} \\ & \mathrm{X}_{\mathrm{d}}=1.0 \text { p.u. } & \mathrm{X}_{\mathrm{q}}=0.6 \mathrm{p} . \mathrm{u} . \\ & \mathrm{X}_{\mathrm{d}}{ }_{\mathrm{d}}=0.3 \text { p.u. } & \\ \text { Excitation system } & \mathrm{Ka}=50 & \mathrm{Ta}=0.05 \mathrm{~s} \\ \text { Transformers } & \mathrm{X}_{\mathrm{tE}}=0.1 \text { p.u. } & \mathrm{X}_{\mathrm{E}}=\mathrm{X}_{\mathrm{B}}=0.1 \mathrm{p} . \mathrm{u} . \\ \text { Transmission lines } & \mathrm{X}_{\mathrm{T} 1}=1.0 \text { p.u. } & \mathrm{X}_{\mathrm{T} 2}=1.3 \mathrm{p} . \mathrm{u} . \\ \text { Operating condition } & \mathrm{P}=0.9115 \mathrm{p} . \mathrm{u} . & \mathrm{Q}=0.2765 \mathrm{p} . \mathrm{u} . \\ & \mathrm{Vt}=1.032 \mathrm{p} . \mathrm{u} . & \\ & \mathrm{Vb}=1.0 \mathrm{p} . \mathrm{u} . & \mathrm{F}=60 \mathrm{~Hz} \\ \text { UPFC Parameters } & \mathrm{m}_{\mathrm{E}}=1.0 & \mathrm{~m}_{\mathrm{B}}=0.1 \\ & \delta_{\mathrm{E}}=28.1^{\circ} & \delta_{\mathrm{B}}=-21.1^{\circ} \\ \text { DC link parameters } & \mathrm{V}_{\mathrm{dc}}=2 \mathrm{p} . \mathrm{u} . & \mathrm{C}_{\mathrm{dc}}=3 \mathrm{p} . \mathrm{u} .\end{array}$

\section{References}

[1] Basler, M.J. Schaefer, R.C. Understanding Power System Stability. IEEETransactions on Industry Applications. March/April 2008; 44(2): 463-474.

[2] [IEEE/CIGRE Joint Task Force on Stability Terms and Definitions. Definition and Classification of Power System Stability. IEEE Transactions on Power Systems. May 2004; Vol. 19(2): 1387-1401.

[3] A Nabavi-Niaki and M R Iravani., "Steady-state and Dynamic Models of Unified Power Flow Controller (UPFC) for Power System Studies," IEEE Transactionson Power Systems, vol 11, no 4, November 1996, p 1937.

[4] K S Smith, L Ran and J Penman, "Dynamic Modelling of a Unified Power Flow Controller," IEE ProceedingsC, vol 144, no 1, January 1997, p 7.

[5] T Makombe and N Jenkins. "Investigation of a Unified Power Flow Controller," IEE Proceedings- C, vol 146, no 4, July 1999, p 400.

[6] Haifeng Wang. A Unified-model for the analysis of FACTS Devices in damping power system oscillations-Part-III; Unified power flow controller. IEEE-Transactions-PD. July 2000; 15(3): 978-983.

[7] H. F. Wang, F. J. Swift, "A Unified Model for the Analysis of FACTS Devices in Damping Power System Oscillations Part I Single-machine Infinite-bus Power Systems," IEEE Transactionson PowerDelivery, Vol. 12, No. 2, April, 1997, pp. 941-946.

[8] H F Wang. "Damping Function of Unified Power Flow Controller," IEE Proceedings-C, vol 146, no 1, January 1999 , p 81 .

[9] D.Harikrishna, N.V.Srikanth. "Unified Philips-Heffron Model of Multi-Machine Power System equipped with PID damping controlled SVC for Power Oscillation Damping”. IEEE India Conference (INDICON) 2009: pp 481-484.

[10] D.Harikrishna, R.S.Dhekekar, N.V.Srikanth. "A novel approach to dynamic stability enhancement using PID damped fuzzy susceptance controlled SVC". IEEE 
Power System Conference and Exposition PSCE 2011, March 2011, pp. 1-6.

[11] P.M.Anderson, A.A. Fouad. Power System Control and Stability. The IOWA state university press, AMES, IOWA, USA.

[12] Narain G. Hingorani and Laszlo Gyugyi, UNDERSTANDINGFACTS. IEEE Press, New York, 2000.

\section{Biographies}

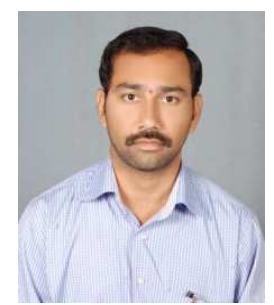

B. Vijay Kumar was born in Warangal, India, in April 1978. He received the B. Tech degree in Electrical \& Electronics Engineering and $M$. Tech degree in Power Systems Engineering from National Institute of Technology, Warangal, India, in 2002 and 2008, respectively. $\mathrm{He}$ is currently working towards the Ph.D degree in Power Systems at National Institute of Technology, Warangal, India. His Current research interest includes Enhancement of Power System Stability using FACTS devices and AI techniques. $\mathrm{He}$ is a member of the Institution of Engineers, India,
[13] N.Tambey, M.L.Kothari "Damping of Power System Oscillations with Unified Poiwer Flow Controller (UPFC)".IEE Proc.-Gener. Transm. Distrib., Vol. 150, No.2, March 2003,pp. 129-140.

[14] M.Sreedevi, P.Jenopaul "Fuzzy Based Controller Damping Inter-Area Oscillations Using UPFC'.IJEPE,Vol.5, Issue3, 2011,pp.125-130.

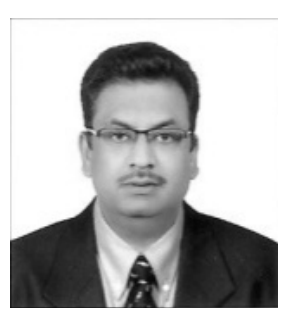

N. V. Srikanth was born in Vijayawada, India, in 1966. He received the B. Tech degree in Electrical \&Electronics Engineering from College of Engineering, Osmania University, Hyderabad, India, in 1988, and his M. Tech and Ph.D degrees in Power Systems Engineering from National Institute of Technology, Warangal, India, in 1999 and 2007, respectively. Currently, he is an Associate professor in the Department of Electrical Engineering, National Institute of Technology, Warangal, India. He has 25 papers in journals, and International/ National conferences. His areas of research interests include Fuzzy logic applications in power systems, power system stability\& control, HVDC transmission systems, and their impact on power system stability. Dr. Srikanth is an active member in many professional organizations. He is a member of IEEE, a member of the Institution of Engineers, India, and a lifetime member of ISTE 